\title{
Water Hammer Investigation of the Shut-Down of a High-Head Hydropower Plant at Very High Reynolds Number Flows
}

\author{
Uroš Karadžić1, ${ }^{*}$ - Anton Bergant2,3 - Danica Starinac ${ }^{4}$ - Boško Božovićc 5 \\ 1 University of Montenegro, Montenegro \\ ${ }^{2}$ Litostroj Power d.o.o., Slovenia \\ 3 University of Ljubljana, Faculty of Mechanical Engineering, Slovenia \\ 4Jaroslav Černi Institute, Serbia \\ 5Electric Power Supply Company, Montenegro
}

\begin{abstract}
This paper investigates water hammer phenomena in a refurbished high-head hydropower plant (HPP) Perućica, Montenegro during shut-down of the entire plant (i.e., the simultaneous closure of the seven Pelton turbine units). An in-situ measuring campaign during a number of steady and unsteady conditions has been performed on the plant's open channel, pressurized and tail race sub-systems with the primary goal of defining measures that will enable the achievement of the plant's installed capacity. In-house software written in Visual Fortran and based on the method of characteristics (MOC) has been developed. The closure of the Pelton turbine distributors is modelled with the two-speed closing law. Dissipation torques in the turbine housing and shaft bearings are considered in the calculation of the Pelton turbine unit rotational speed change. Numerical results given for standard quasi-steady and convolution-based unsteady friction models are compared with the results of measurements at flows with very high initial Reynolds numbers (larger than 107). The developed numerical model shows good agreement with the results of site measurements. It is shown that the unsteady friction has a small impact on pressure histories in Perućica HPP.
\end{abstract}

Keywords: water hammer, high-head hydropower plant, Pelton turbine, emergency shut-down, high Reynolds number

\footnotetext{
Highlights

- Water hammer during emergency shut-down of the high-head hydropower plant was investigated.

- A numerical model based on the method of characteristics was developed.

- Verification of the numerical model was done by comparison of measurements that have been made throughout the plant system.

- $\quad$ Pressure histories at the downstream end of three parallel penstocks, penstock inlet valve chambers, surge tank as well as turbine speed changes were investigated and commented on.

- The influence of unsteady friction is of minor importance for relatively slow transients considered at initially high Reynolds numbers (larger than 107).
}

\section{INTRODUCTION}

Water hammer in hydropower plants (HPPs) is caused by the closing or opening of the turbine unit distributors, the operation of the safety shutoff valves, as well as unwanted turbine runaway. Careful water hammer control is essential to ensure reliable operation of hydropower plants. If this is not provided, severe problems may arise in operation, damage to individual components of the system may occur or, in the worst case, accidents with human casualties may happen [1] to [5]. Modelling and analysis of extreme hydraulic transients (plant emergency shut-down) in new or refurbished HPPs are of utmost importance because, in this way, extreme values of pressures that may occur during system exploitation can be determined. Based on these values, closing and opening times of the turbine units' distributors are devised, as well as dimensioning of the system components is done.

The objective of this paper is to investigate and discuss water hammer effects in Perućica HPP,
Montenegro during the entire plant emergency shutdown, i.e., simultaneous closure of all seven Pelton turbine units. The units are installed in three parallel penstocks (each of about $2 \mathrm{~km}$ long) that are coupled to a concrete tunnel (about $3.3 \mathrm{~km}$ long) with a surge tank. Previously, measurements of the first and second Pelton turbines in one penstock only have been investigated [6]. This paper presents new results at much higher Reynolds number flows (higher than $10^{7}$ ) than previously presented (in order of $10^{6}$ ).

In the first part of the paper, mathematical tools for solving water hammer equations are presented [7] and [8]. Friction losses in the plant's penstocks are calculated with two different models: (1) standard quasi-steady (QSF) and (2) convolutionbased unsteady friction model (CBM) [9] and [10]. Turbine speed change during emergency shut-down is calculated, taking into account dissipative torques, including the shaft-bearing friction torque and ventilation losses in the turbine housing [6]. In the second part of the paper, comparisons of numerical 
and field test results are made for the case of the entire plant shut-down. The results given for pressure changes in the plant's penstocks, feeding tunnel, as well as water level fluctuations in surge tank and turbine speed change, are investigated and commented on.

\section{THEORETICAL MODELLING}

Water hammer refers to the transmission of pressure waves in liquid-filled pipelines resulting from a change in flow velocity. For most engineering applications, simplified water hammer equations neglecting the convective terms are used in the analysis [7] and [8].

$$
\begin{gathered}
\frac{\partial H}{\partial t}+\frac{a^{2}}{g A} \frac{\partial Q}{\partial x}=0, \\
\frac{\partial H}{\partial x}+\frac{1}{g A} \frac{\partial Q}{\partial t}+\frac{f Q|Q|}{2 g D A^{2}}=0,
\end{gathered}
$$

where, $H$ is a piezometric head (head), $t$ time, $a$ the pressure wave speed, $g$ the gravitational acceleration, $A$ pipe area, $Q$ the discharge, $x$ the axial co-ordinate, $f$ the Darcy-Weisbach friction factor, and $D$ the pipe diameter. All the symbols are defined as they first appear in the paper. For solving Eqs. (1) and (2), the staggered (diamond) grid [7] in applying the method of characteristics is used in this paper.

\subsection{Friction Losses}

For evaluation of friction factor in Eq. (2), the standard quasi-steady approach is traditionally used. This model does not give good results for fast transients, and it has been shown that inclusion of unsteady friction significantly improves numerical results [11] and [12]. To date, a little has been published about unsteady friction effects in real hydro systems [6] and [13]. Duan et al. [14] investigated the relative importance of unsteady friction in the pipelines taking into account pipe size and length. They introduced dimensionless parameter $I_{D}=f V_{0} L /(a D)$ and concluded that the effects of unsteady friction for fast transients (sudden and complete valve closure) are essential when $I_{D}<0.10$. However, unsteady friction may be significant in some cases, such as behaviour close to resonance. In case of plant emergency shut-down, unsteady friction has to be investigated and included into numerical model since it has been shown that the model with unsteady friction included gives some higher values of maximum system pressure than the QSF model does [6]. The friction factor $f$ can be expressed as the sum of the quasi-steady part $f_{q}$ and the unsteady $\operatorname{part} f_{u}[15]$ and [16],

$$
f=f_{q}+f_{u} .
$$

The QSF factor is calculated and updated at every time step, according to standard formulae for evaluating quasi-steady friction losses. For the determination of the unsteady friction factor, a CBM is used for simulation in this paper [9]. The traditional implementation of CBM in the method of characteristics (MOC) results in many convolution calculations that increase the computational time dramatically. However, the computationally efficient unsteady friction factor can be defined by using approximated weighting functions embedded in a finite sum of $N_{k}$ functions $y_{k}(t)$ as originally proposed by Trikha [17] in his three-function approximation of Zielke's weighting function for transient laminar flow,

$$
f_{u}=\frac{32 v A}{D Q|Q|} \sum_{k=1}^{N_{k}} y_{k}(t)
$$

A number of authors have developed multifunction approximations with lesser or higher degrees of accuracy. Approximations have been developed for Zielke's original weighting function for transient laminar flow and numerous weighting functions for transient turbulent flow [10], [18] and [19]. The widely used approximation of Vítkovský et al. [20] is accurate over a broad range of dimensionless times $\Delta \tau=\Delta t 4 v / D^{2} \quad\left[10^{-6}, 10^{-1}\right]$. For lower $\Delta \tau$ values, Urbanowicz [21] and [22] developed a computationally efficient and accurate approximation of weighting functions that should be used when $\Delta \tau \leq 10^{-6}$.

\subsection{Pelton Turbine Model}

Pelton turbine output is regulated by control of discharge that acts on the turbine wheel. Discharge is adjusted by closing or opening the nozzle throat by means of a needle (Fig. 1) and with an appropriate position of the jet deflector.

The discharge through the nozzle is only dependent on the position of the needle valve, and it does not depend on the turbine unit rotational speed as is the case in reaction water turbines. Therefore, the water hammer equations and the dynamic equation of the unit rotating parts can be solved separately. In this way, the instantaneous head at the nozzle inlet and instantaneous discharge through the nozzle are calculated with the MOC, and these values are used as an input in the solution method for the dynamic equation of the unit rotating parts. The instantaneous 


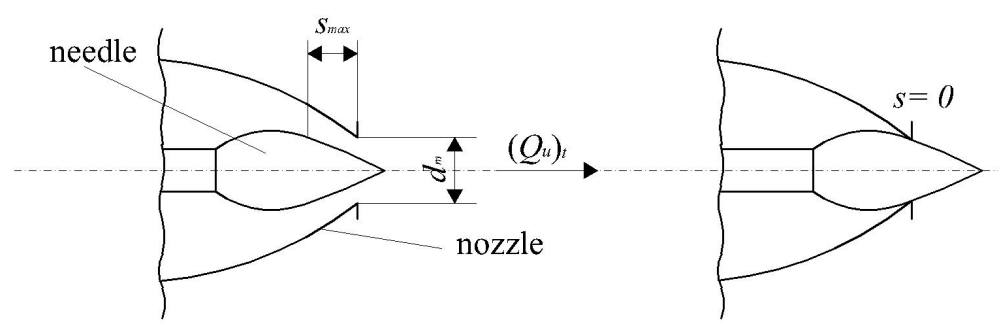

Fig. 1. Pelton turbine distributor (needle valve)

discharge through the nozzle $\left(\left(Q_{u}\right)_{t}\right)$ is determined from the following relation [6]:

$$
\left(Q_{u}\right)_{t}=K_{Q} A_{m} \sqrt{2 g\left(H_{u, t}-H_{d}\right)}
$$

where $K_{Q}$ is nozzle discharge coefficient, $A_{m}$ is nozzle area $\left(A_{m}=\pi d_{m}{ }^{2} / 4\right), d_{m}$ is nozzle diameter, $H_{u, t}$ is the instantaneous head at the nozzle inlet, and $H_{d}=$ const. is head downstream the nozzle. The nozzle discharge coefficient is a function of the nozzle opening. The needle closing law is expressed as:

$$
s=\tau \cdot s_{\max },
$$

where $\tau$ is a dimensionless nozzle opening and $s_{\max }$ maximum needle stroke. The procedure for calculating the needle closing run is described in detail in [6].

The emergency shut-down of the turbine unit is the most severe normal operating transient regime [8]. The turbine is disconnected from the electrical grid followed by simultaneous gradual full-closure of the needle(s) and rapid activation of the jet deflector(s). The equation that describes the dynamic behaviour of the Pelton turbine unit rotating parts during emergency shut-down is [6]:

$$
T_{a} \frac{d \varphi}{d t}=m_{h}-m_{f r}-m_{\text {air }},
$$

where $T_{a}$ is the mechanical starting time [8], $\varphi=\left(n-n_{r}\right) / n_{r}$ is the relative speed change, $n$ is the turbine rotational speed (traditionally in $\mathrm{rpm}$ ), $r$ defines the rated conditions, $m_{h}$ is dimensionless hydraulic torque, $m_{f r}$ is dimensionless shaft bearing friction torque, and $m_{\text {air }}$ is dimensionless fluid damping torque (ventilation losses in the turbine housing); see [6] for details. Eq. (7) can be solved analytically [6].

\subsection{Note on Other Boundary Conditions}

Theoretical models for the reservoirs, orifice type surge tank, and branching junction (trifurcation) can be found in standard water hammer textbooks [7] and [8].

\section{PERUĆICA FLOW-PASSAGE SYSTEM}

Perućica HPP was built in the mid-1950s. The flow-passage system (Fig. 2) is a complex system comprised of an intake structure with guard gate,

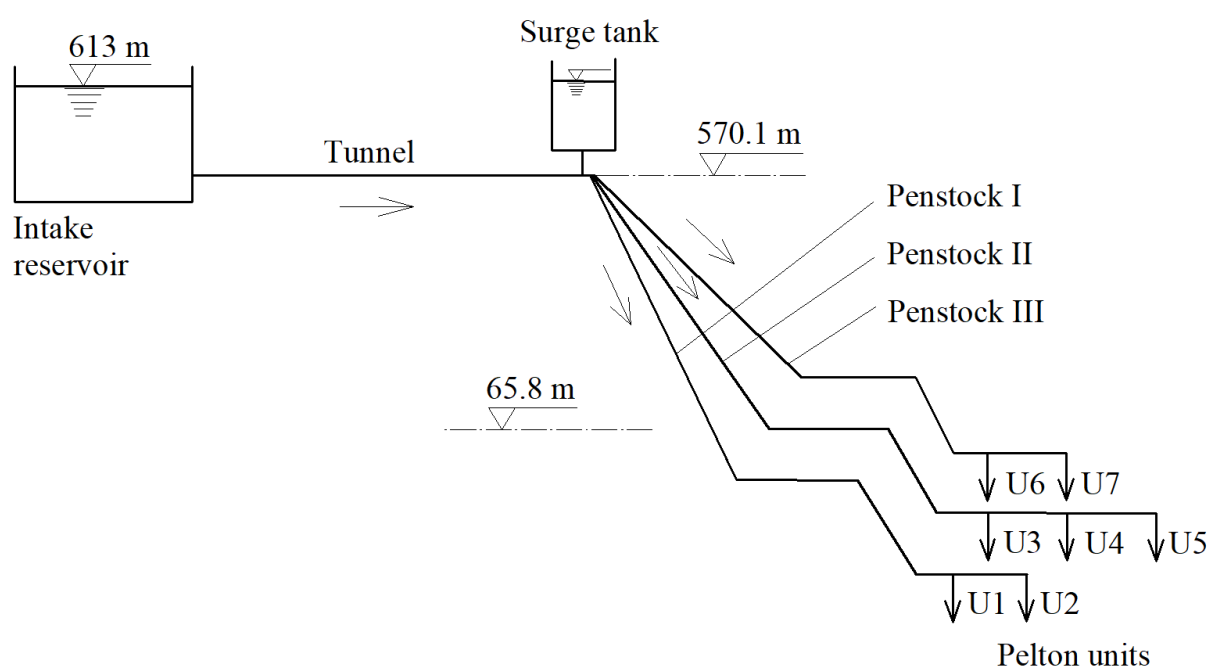

Fig. 2. Layout of Perućica HPP, Montenegro 

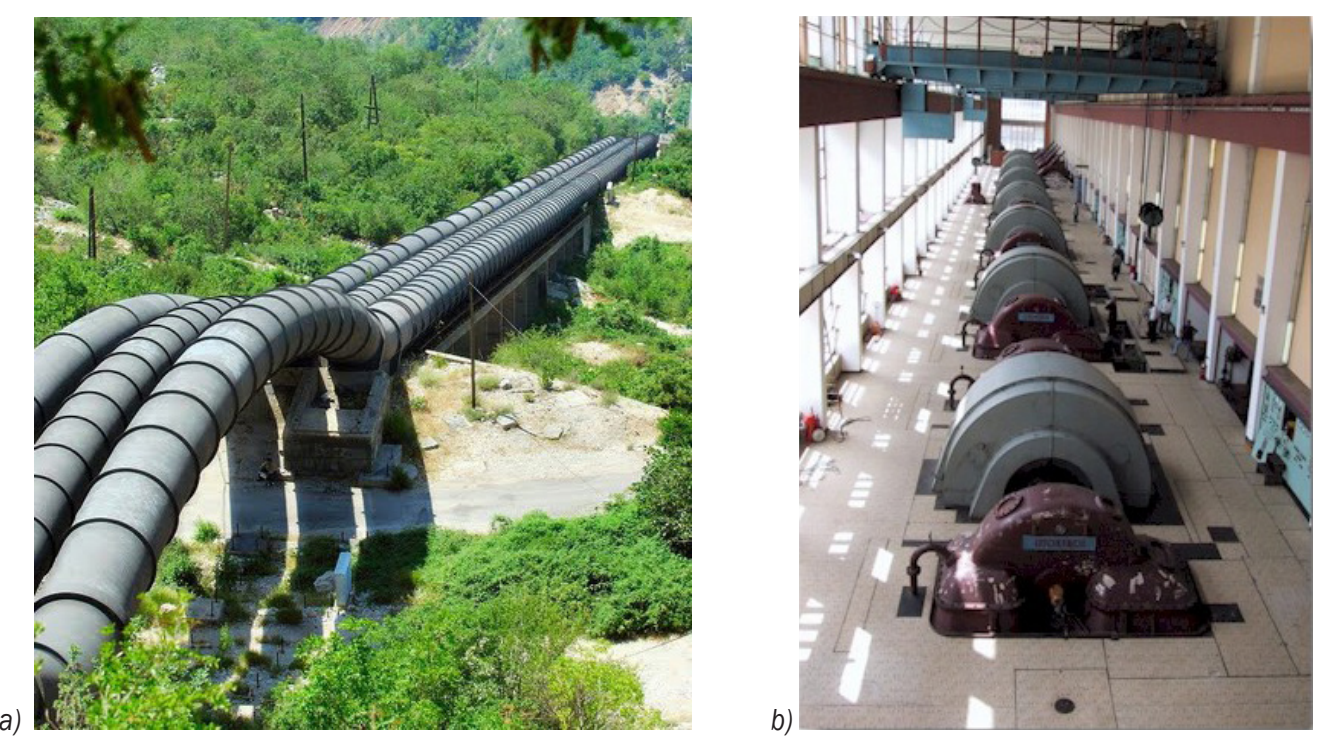

Fig. 3. Layout of a) three parallel penstocks and b) powerhouse with seven twin-type Pelton units in Perucica HPP

concrete tunnel (length $L_{T}=3335 \mathrm{~m}$, diameter $D_{T}=4.8 \mathrm{~m}$ ), orifice type surge tank (orifice head loss coefficients: $\zeta_{\text {in }}=1.65$ and $\zeta_{\text {out }}=2.48$ during inflow and outflow, respectively) of cylindrical cross-section $\left(D_{S T}=8.0 \mathrm{~m}\right)$ with an expansion at elevation $z=611.0$ $\mathrm{m}\left(D_{S T}=12.0 \mathrm{~m}\right)$ and overflow (elevation: $z_{o v}=628.0$ $\mathrm{m}$; width of the overflow weir: $b_{o v}=7.98 \mathrm{~m}$ with discharge coefficient $\mu_{o v}=0.4$ ) and three parallel steel penstocks (Fig. 3a) with horizontal-shaft twin-type Pelton turbines built at their downstream ends (Fig. 3b).

The equivalent length and diameter [8] of Penstock I are $1920 \mathrm{~m}$ and $1.96 \mathrm{~m}$, respectively; for Penstock II $1966 \mathrm{~m}$ and $2.16 \mathrm{~m}$; for Penstock III 2014 $\mathrm{m}$ and $2.57 \mathrm{~m}$. Penstock I feeds two turbine units (U1 and U2) with rated unit power of 39 MW; Penstock II feeds three turbine units (U3, U4 and U5) of 39 MW each; Penstock III feeds two units (U6 and U7) of 59 MW each. The distributors of the first four units (U1 to U4) have been already refurbished. The maximum water level at the intake is $613 \mathrm{~m}$, and the minimum one is $602.5 \mathrm{~m}$. The Pelton wheel diameter of units U1 to U5 is $D_{k}=2400 \mathrm{~mm}$, and is $D_{k}=2100 \mathrm{~mm}$ for units U6 and U7. The rotational speed of U1 to U5 is $n=375 \mathrm{~min}^{-1}$, and of $\mathrm{U} 6$ and $\mathrm{U} 7$ is $n=428 \mathrm{~min}^{-1}$.

\subsection{Instrumentation}

Recently, the Hydraulic Department of the Jaroslav Černi Institute, Belgrade, Serbia, has performed comprehensive in-situ measurements (water level, discharge, pressure, displacement, stress, and vibrations) at different locations throughout the entire HPP system. Numerous steady-state and unsteady state scenarios have been tested, through continuous and simultaneous measurements at all measurement stations including intake structure (feeding channels and reservoir), the tunnel with the surge tank, three parallel penstocks with seven Pelton turbine units, and the outlet structure [23] and [24]. During shut-down of the entire power plant, all influential quantities were continuously measured including pressures at the inlet of the turbines, strokes of the needles and of the jet deflectors, units' rotational speeds, pressures at the downstream end of the tunnel and the upstream end of the penstocks (penstock valve chambers) as well as water level in the surge tank. Pressures at the upstream end of the distributors were measured with a Cerabar T PMP 131-A1101A70 Endress+Hauser absolute high-pressure piezoresistive transducers (pressure range 0 bar to 100 bar, uncertainty in measurement $\pm 0.5 \%$ ). Pressures at the valve chamber were measured with a Cerabar $T$ PMP 131-A1B01A1S Endress+Hauser absolute highpressure piezoresistive transducers (pressure range 0 bar to 10 bar, uncertainty in measurement $\pm 0.5 \%$ ). The needle stroke and the stroke of the jet deflector were measured with Balluff BTL5-S112-M0175-B-532 and Balluff BTL5-S112-M0275-B-532 displacement transducers, respectively. The uncertainty of these sensors is $\pm 0.03 \mathrm{~mm}$. The turbine rotational speed was measured using a Balluff BES M18MI-PSC50B-S04K inductive sensor (uncertainty in measurement \pm 0.03 $\%)$. The surge tank water level was measured with a 
Micropilot M FMR240 Endress + Hauser radar sensor (range $0 \mathrm{~m}$ to $70 \mathrm{~m}$, uncertainty in measurement \pm 3 $\mathrm{mm})$. The initial discharges in the penstocks were measured with Prosonic Flow 93W, Endress+Hauser ultrasonic flowmeters (velocity range up to $15 \mathrm{~m} / \mathrm{s}$, uncertainty in measurements $\pm 0.5 \%$ ).

\section{COMPARISON OF NUMERICAL AND IN-SITU TEST RESULTS}

During the campaign, the following steady and unsteady regimes were investigated: the unit startup and stop, load acceptance and reduction, load rejection under governor control and emergency shutdown, and closure of turbine safety valves against the discharge.

In this paper, the simultaneous emergency shutdown of all seven Pelton turbine units is investigated. The total initial power output of the plant was 303.54 MW, and discharge in the feeding tunnel was $Q_{T}=70.24 \mathrm{~m}^{3} / \mathrm{s}$. The measured needle closing times and initial opening of the nozzles are presented in Table 1. Initials capacities and discharges per unit are shown in Table 2 in which the initial unit's discharges were calculated from the known initial capacity (plant SCADA system), measured net head and measured initial opening of the nozzles. Measured initial discharges in the penstocks were $Q_{\mathrm{I}}=17.4$ $\mathrm{m}^{3} / \mathrm{s}, Q_{\mathrm{II}}=25.38 \mathrm{~m}^{3} / \mathrm{s}, Q_{\mathrm{III}}=27.46 \mathrm{~m}^{3} / \mathrm{s}$. Flows in the feeding tunnel and penstocks were turbulent with large Reynolds numbers, $\operatorname{Re}_{T}=1.86 \times 10^{7}$, $\mathrm{Re}_{\mathrm{I}}=1.13 \times 10^{7}, \mathrm{Re}_{\mathrm{II}}=1.5 \times 10^{7}$, and $\mathrm{Re}_{\mathrm{III}}=1.36 \times$ $10^{7}$. Initial steady friction factors in the tunnel and penstocks are $f_{0 T}=0.0146, f_{0 \mathrm{I}}=0.0105, f_{0 \mathrm{II}}=0.0118$ and $f_{0 I I I}=0.0152$. The water level at the intake was $z_{R}=603.6 \mathrm{~m}$. The estimated pressure wave speeds in the tunnel and three penstocks are $a_{T}=1354 \mathrm{~m} / \mathrm{s}$, $a_{\mathrm{I}}=1148 \mathrm{~m} / \mathrm{s}, a_{\mathrm{II}}=1123 \mathrm{~m} / \mathrm{s}$ and $a_{\mathrm{III}}=1152 \mathrm{~m} / \mathrm{s}$, respectively [6]. The basic time step in the staggered grid MOC code was $\Delta t=0.04 \mathrm{~s}$. Numerical results obtained from the standard QSF and the unsteady friction $\mathrm{CBM}$ are compared with the results of measurements. Dimensionless times used in CBM (see Section 1.1) for the tunnel, and Penstocks I, II, and III are $\Delta \tau=\left\{0.0069 \times 10^{-6}, 0.0414 \times 10^{-6}, 0.0342 \times 10^{-6}\right.$, $\left.0.0242 \times 10^{-6}\right\}$, respectively. Consequently, the Urbanowicz approximation model in CBM [21] and
Table 1. Needle valve closing times and initial opening of the nozzles

\begin{tabular}{cccc}
\hline \multirow{2}{*}{$\begin{array}{c}\text { Unit and } \\
\text { needle }\end{array}$} & $\begin{array}{c}\text { Closing } \\
\text { time [s] }\end{array}$ & \multicolumn{2}{c}{ Nozzle opening } \\
\cline { 3 - 4 } U1n & $S_{0}[\mathrm{~mm}]$ & {$[\%]$} \\
\hline U1n $_{\mathrm{b}}$ & 71.5 & 133.2 & 88.77 \\
\hline U2na & 70.0 & 133.2 & 88.77 \\
\hline U2nb & 73.5 & 135.9 & 90.62 \\
\hline U3na & 70.0 & 135.9 & 90.62 \\
\hline U3nb & 49.0 & 135.8 & 90.52 \\
\hline U4na & 44.0 & 135.8 & 90.52 \\
\hline U4nb & 70.0 & 141.2 & 94.17 \\
\hline U5na & 67.0 & 141.2 & 94.17 \\
\hline U5nb & 40.0 & 167.7 & 86.0 \\
\hline U6na & 48.0 & 167.7 & 86.0 \\
\hline U6nb & 108.5 & 165.0 & 99.42 \\
\hline U6nc & 86.0 & 165.2 & 99.55 \\
\hline U6nd & 114.0 & 165.3 & 99.58 \\
\hline U7na & 95.0 & 165.4 & 99.65 \\
\hline U7nb & 95.0 & 160.8 & 96.88 \\
\hline U7nc & 67.5 & 161.2 & 97.12 \\
\hline U7nd & 116.5 & 161.2 & 97.12 \\
\hline & 69.0 & 161.2 & 97.12 \\
\hline
\end{tabular}

[22] has been used. Duan's parameter [14] for the tunnel and three penstocks is $I_{D}=\{0.014,0.0834$, $0.0847,0.03\}$. The needle valve closure times are slow (see Table 1), and Duan's parameter cannot be used for this case. However, there is a need to extend Duan's parameter for cases with slower valve closure times $\left(0<t_{c} \leq 2 L / a, t_{c}>2 L / a, t_{c}>10 L / a\right)$.

A comparison of calculated and measured heads at the downstream end of Penstock I and needle strokes is shown in Fig. 4. The maximum measured head is obtained at the end of the nozzle closure process, and it is $643.5 \mathrm{~m}$ with a head-rise of $75.1 \mathrm{~m}$. The maximum heads obtained with numerical models have some higher values and are equal to $644 \mathrm{~m}$ (QSF, Fig. 4b) and $644.6 \mathrm{~m}$ (CBM, Fig. 4c). All maximum head values are below the maximum permissible system head of $668 \mathrm{~m}$. The closing time is much larger than the water hammer reflection time of $2 L_{\mathrm{I}} / a_{\mathrm{I}}=3.34$ s. It should be noted that, in the event of unit shutdown from smaller initial powers, the closing time of the nozzles can be within the water hammer reflection time, which can cause an unacceptable head increase.

Table 2. The initial unit's powers and discharges

\begin{tabular}{ccccccccc}
\hline & U1 & U2 & U3 & U4 & U5 & U6 & U7 & Total \\
\hline $\mathrm{P}[\mathrm{MW}]$ & 37.9 & 37.7 & 36.9 & 37.3 & 38 & 59.1 & 56.6 & 303.54 \\
\hline $\mathrm{Q}[\mathrm{m} 3 / \mathrm{s}]$ & 8.65 & 8.75 & 8.64 & 8.74 & 8.0 & 13.8 & 13.66 & 70.24 \\
\hline
\end{tabular}



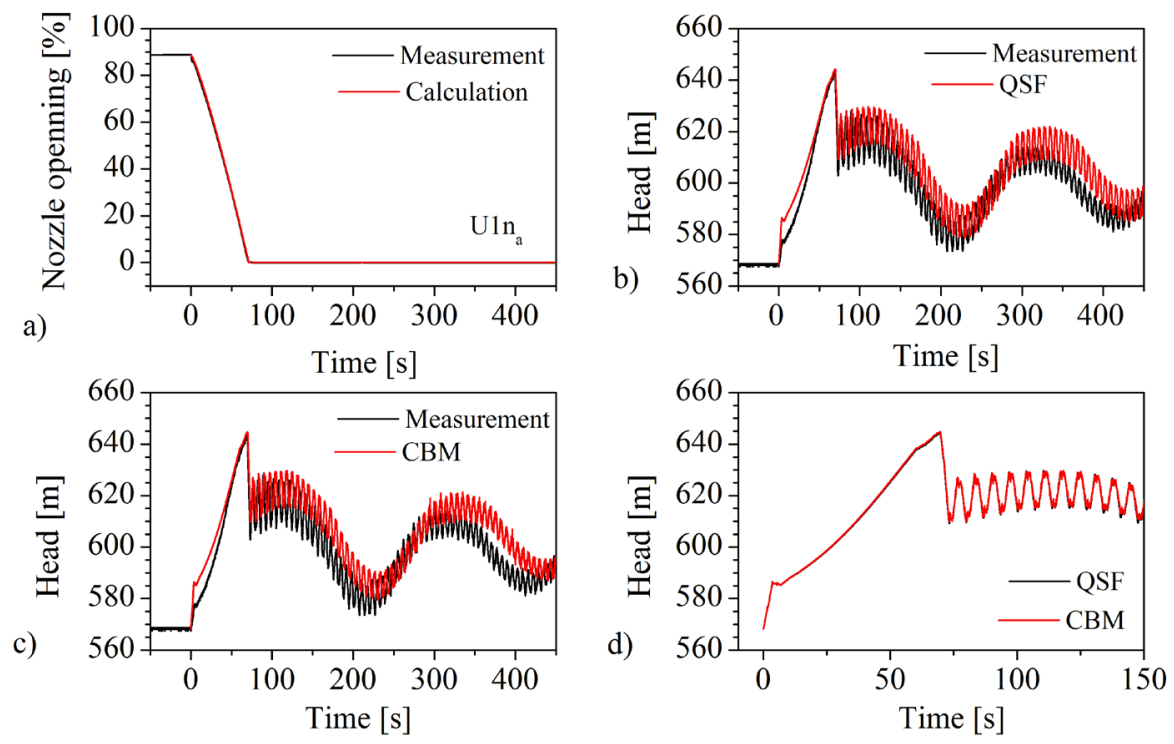

Fig. 4. Comparison of piezometric heads (heads) and needle stroke (s) at the end of penstock I (datum level $\mathrm{z}=0.0 \mathrm{~m}$; time step $\Delta t=0.04 \mathrm{~s}$ )

Particular attention should be paid to this problem [25]. After nozzles are closed numerical models give some higher head values but, generally, they are in good agreement with the results of the measurements. The results obtained using QSF and CBM numerical models are practically the same in the first $150 \mathrm{~s}$ of transient processes (Fig. 4d) and, after that time, the CBM model better attenuates pressure waves and produces results that are closer to the measurements (Figs. $4 \mathrm{~b}$ and c).

Fig. 5 shows a comparison of measured and calculated heads and needle strokes at the downstream end of Penstock II. Like in Penstock I, the maximum head occurs after the nozzles were closed, and it is $641.0 \mathrm{~m}$ with a head increase of $78.6 \mathrm{~m}$. The maximum head values obtained with the QSF and $\mathrm{CBM}$ numerical models are in good agreement with a)
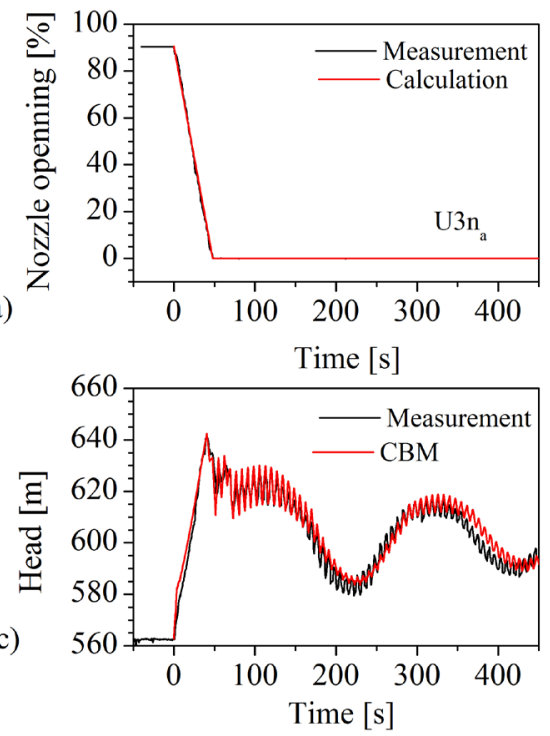

b)
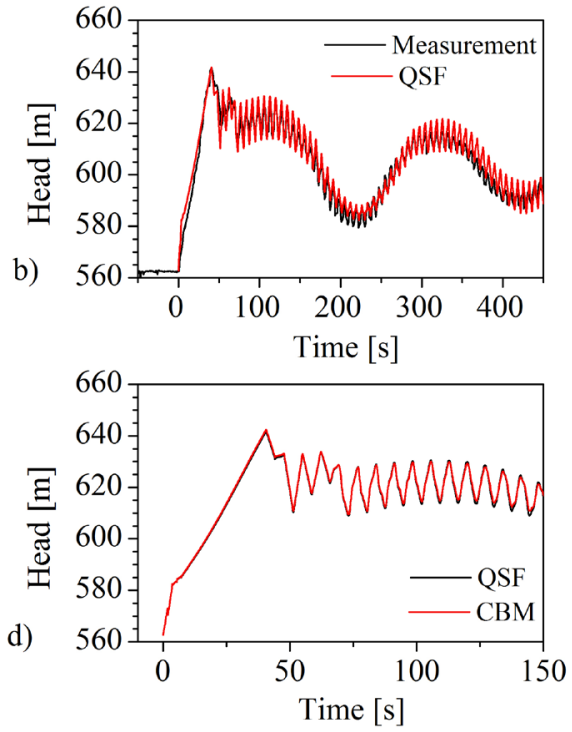

Fig. 5. Comparison of piezometric heads (heads) and needle stroke (s) at the end of penstock II (datum level $\mathrm{z}=0.0 \mathrm{~m}$; time $\operatorname{step} \Delta \mathrm{t}=0.04 \mathrm{~s}$ ) 
measured values, and they are $641.5 \mathrm{~m}$ and $642.0 \mathrm{~m}$, respectively (Figs. 5b and c). Calculated and measured values are below the maximum system allowed head of $668 \mathrm{~m}$. The closing time, like in Penstock I, is much larger than the water hammer reflection time of $2 L_{\mathrm{II}} / a_{\mathrm{II}}=3.5$ s. Numerical results show good agreement with the measured results during entire transient period, with the CBM results slightly closer to the measured results (Figs. $5 \mathrm{~b}$ and $\mathrm{c}$ ).

Fig. 6 shows comparisons of heads and needle strokes at the downstream end of Penstock III. Unfortunately, during the experiment, the pressure transducer installed at the downstream end of the Penstock III was damaged; however, the magnitude and shape of measured pressure head histories follow the same path as calculated ones (Figs. $6 \mathrm{~b}$ and c). The head increase in Penstock III obtained with the QSF model is $44.1 \mathrm{~m}$ and is $45.1 \mathrm{~m}$ with the CBM model. The maximum head value given by QSF is $631 \mathrm{~m}$ at time $t=100 \mathrm{~s}$ where the value of the maximum head using the CBM model is $632 \mathrm{~m}$, also at time $t=100 \mathrm{~s}$. It should be noted that in Penstock III, eight nozzles were closed from which the first was closed at $t=67.5$ $\mathrm{s}\left(\mathrm{U} 7 \mathrm{n}_{\mathrm{b}}\right)$ and the last at $t=116.5 \mathrm{~s}\left(\mathrm{U} 7 \mathrm{n}_{\mathrm{c}}\right)$. In this period, uneven head oscillations occurred (Fig. 6d). The pressure wave travels to the surge tank and back and found nozzles with different degrees of opening every time. Consequently, the discharge between Units 6 and 7 is not evenly divided over the duration of the transient process.
A similar situation also occurred in Penstock II (Fig. 5d). The water hammer reflection time of Penstock III is equal to water hammer reflection time of Penstock II i.e. $2 L_{\mathrm{III}} / a_{\mathrm{III}}=3.5 \mathrm{~s}$. The refurbishment of the distributors of units U5 to U7 and their governors is planned, following which the closing time of all nozzles on all units will finally be adjusted so that the nozzles on the individual penstocks have the same closing times. It should be noted that, according to the original project documentation, the closing times for all nozzles for the case of the entire plant shut-down are equal to $80 \mathrm{~s}$.

Let us now examine that pressure head histories at the branching junction that connects the downstream end of the tunnel and the upstream end of the three parallel penstocks (Fig. 2). The surge tank is located $85 \mathrm{~m}$ upstream of the junction. The measured and calculated head changes at the downstream end of the concrete tunnel and the upstream end of the three steel penstocks are shown in Figs. 7 and 8.

The maximum measured heads are: $622.8 \mathrm{~m}$ (tunnel, Fig. 7a), 623.7 m (Penstock I, Fig. 7b), 622.9 $\mathrm{m}$ (Penstock II, Fig. 7c) and $623.5 \mathrm{~m}$ (Penstock III, Fig. 7d). The minimum measured heads in the valve chambers are: $584.5 \mathrm{~m}$ (tunnel), $584.4 \mathrm{~m}$ (Penstock I), $583.8 \mathrm{~m}$ (Penstock II) and $585.1 \mathrm{~m}$ (Penstock III). QSF and CBM give practically the same results with the maximum and minimum head values close to measured one (Figs. 7 and 8). However, there is a phase shift that increases during the time. In that a)
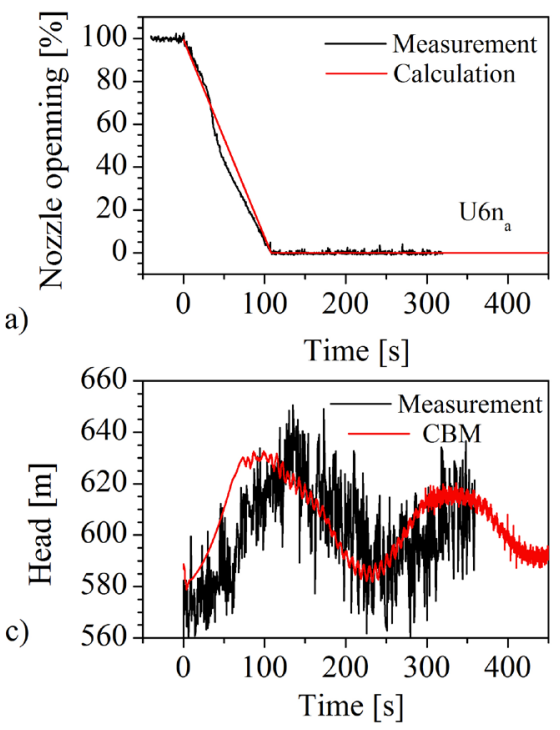
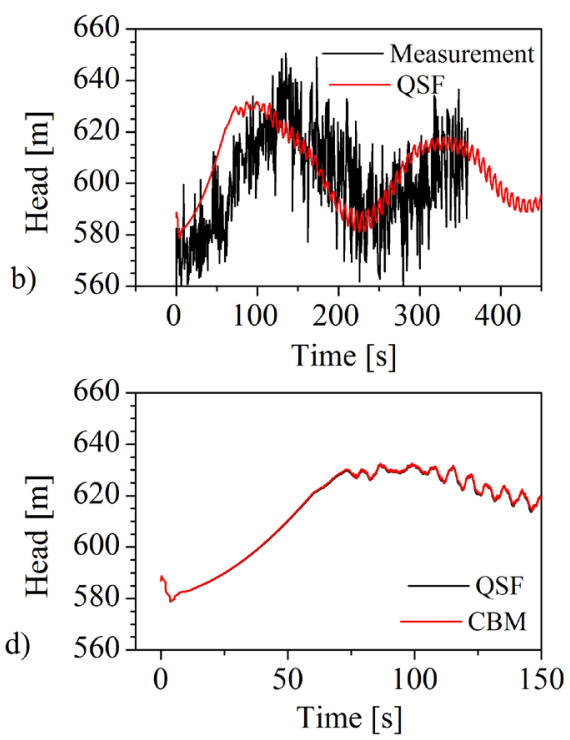

Fig. 6. Comparison of piezometric heads (heads) and needle stroke (s) at the end of penstock III (datum level $\mathrm{z}=0.0 \mathrm{~m}$; time step $\Delta t=0.04 \mathrm{~s}$ ) 

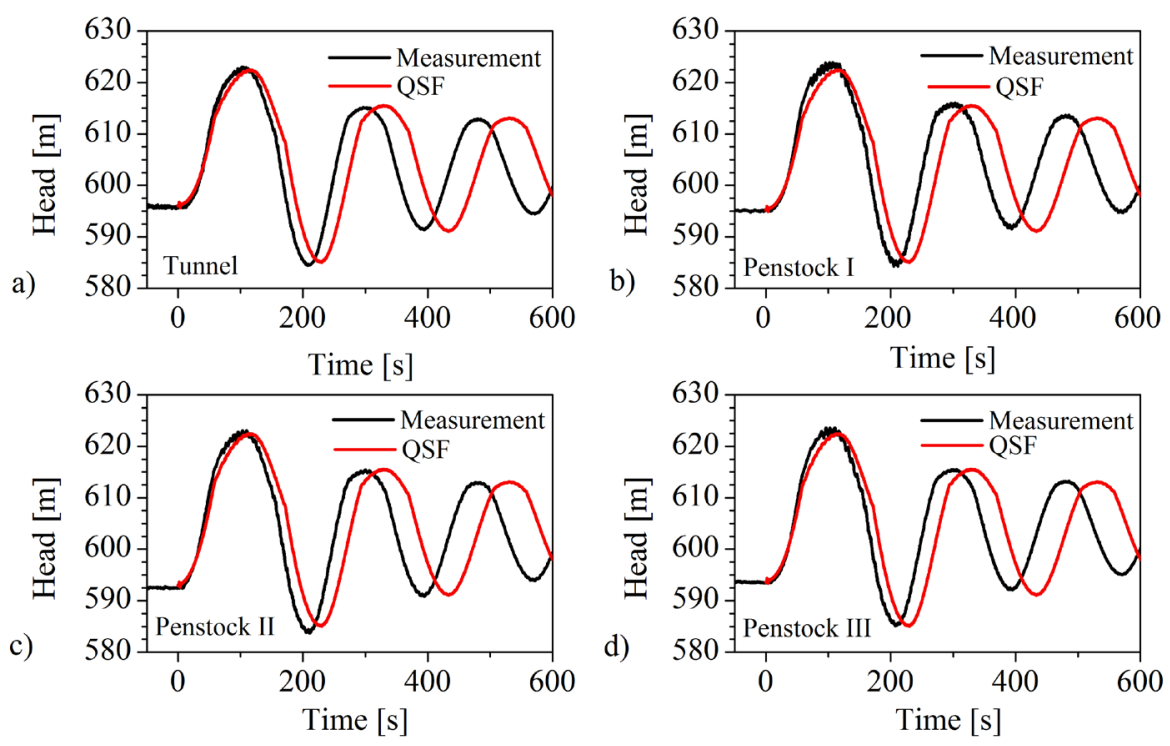

Fig. 7. Comparison of piezometric heads (heads) at the valve chamber (QSF model; datum level $\mathrm{z}=0.0 \mathrm{~m}$; time step $\Delta \mathrm{t}=0.04 \mathrm{~s}$ )
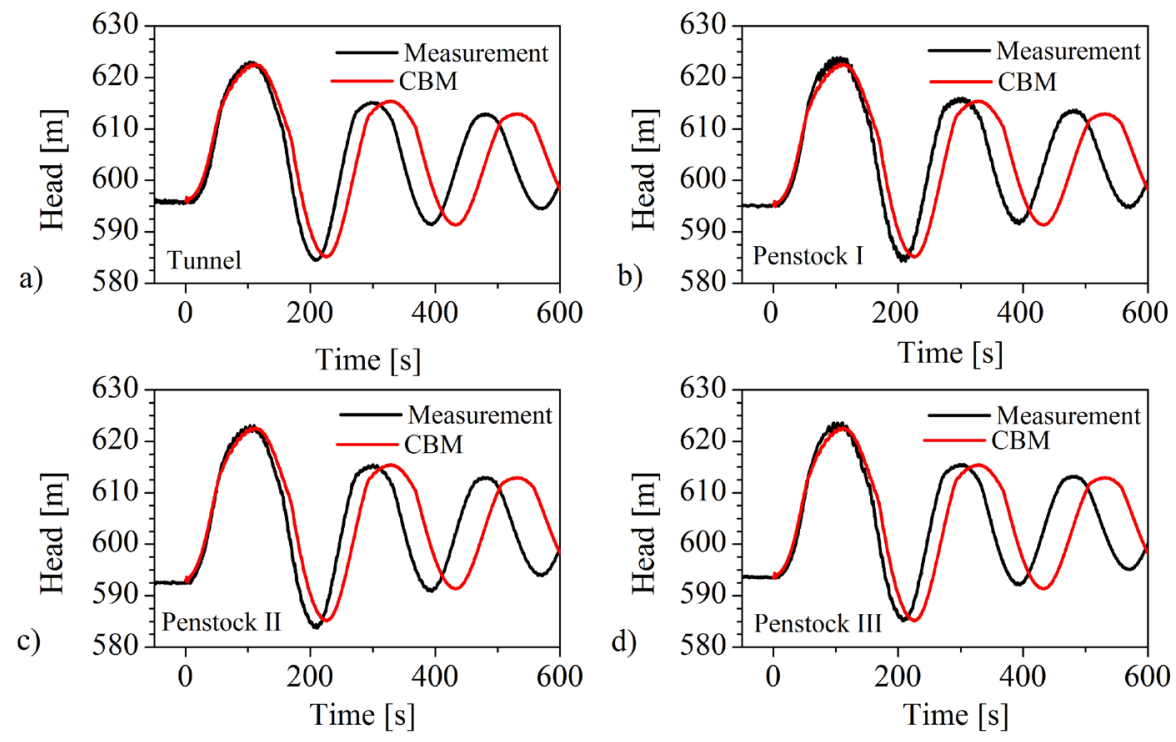

Fig. 8. Comparison of piezometric heads (heads) at the valve chamber (CBM model; datum level z=0.0 m; time step $\Delta \mathrm{t}=0.04 \mathrm{~s}$ )
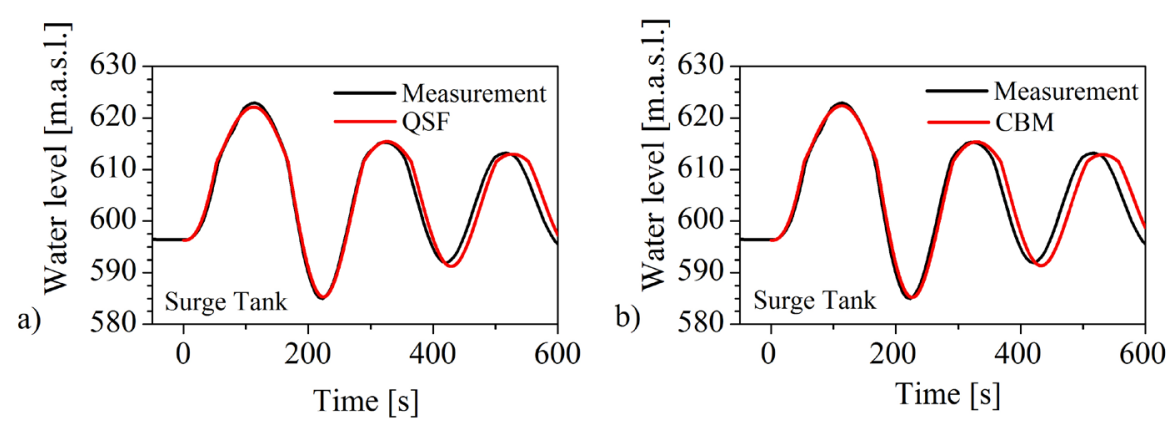

Fig. 9. Comparison of water level in the surge tank (time step $\Delta t=0.04 \mathrm{~s}$ ) 
numerical model coefficients of head losses at the branching junction obtained for the steady flow are used. It may be one of the reasons for the phase shift between the computational and measured results.

The surge tank water-level oscillations are shown in Fig. 9. The maximum water level in the surge tank occurred at time $t=114 \mathrm{~s}$, and it is $623 \mathrm{~m}$; much lower than the overflow elevation of $628 \mathrm{~m}$. The minimum water level in the surge tank occurred at the time $t=223 \mathrm{~s}$, and it is equal to $585 \mathrm{~m}$. There is no danger of the surge tank emptying for the case considered because the surge tank bottom is at an elevation of $577.5 \mathrm{~m}$, i.e., the minimum water level is $7.5 \mathrm{~m}$ above surge tank bottom level. Numerical models show better agreement with the results of measurements than for the flow situation in the downstream end of the junction (Figs. 7 and 8). Only a small discrepancy in the phase shift occurs after $t=360 \mathrm{~s}$. This discrepancy may be attributed to the cumulative numerical differences when a complex boundary condition, such as surge tank trifurcation and three penstocks with different flow rates and friction coefficients, is simulated.

Fig. 10 shows a comparison between the computed and measured turbine rotational speed changes for Units $1,2,3$, and 6. The maximum measured and calculated turbine speed rise for all units occurs at time $t=t_{\text {def }} ; t_{d e f}$ is the jet deflector operating time. The computed maximum turbine rotational speed rise matches the maximum measured value for all units (Fig. 10). After the jet deflector deflects the water into the tailrace, the turbine speed decrease is influenced only by the dissipation torques because the turbine wheel is not affected by the hydraulic torque. For the first four units (U1 to U4), that have been already refurbished, the maximum turbine speed rise is about $10 \%$ and is well below the permissible speed rise of $25 \%$. The experimental dissipation torque is slightly higher for U3 compared with U1 and U2. This can be attributed to increased ventilation losses in the turbine housing due to different tailwater conditions. For the un-refurbished units (U5 to U7), the speed rise is of the same magnitude as the permissible one. The refurbishment of worn out units is foreseen in the near future. The discrepancies between the calculated and measured rotational speed time histories are much higher for the U6 unit and are attributed to larger bearing and ventilation losses.

\section{CONCLUSIONS}

New in-situ experimental and computed results for the case of simultaneous emergency shut-down of seven Pelton turbines in a high-head hydropower plant Perućica, Montenegro are presented. The experiment has been performed at very high Reynolds number flows (larger than $10^{7}$ ) not reported in the available literature. The in-house numerical algorithm is based on the method of characteristics in which the frictional losses are modelled by using the QSF (standard quasi-steady friction) and the CBM (convolutionbased unsteady friction) models. The algorithm first computes water hammer in the fluid conveyance system and then (separately) the turbine rotational
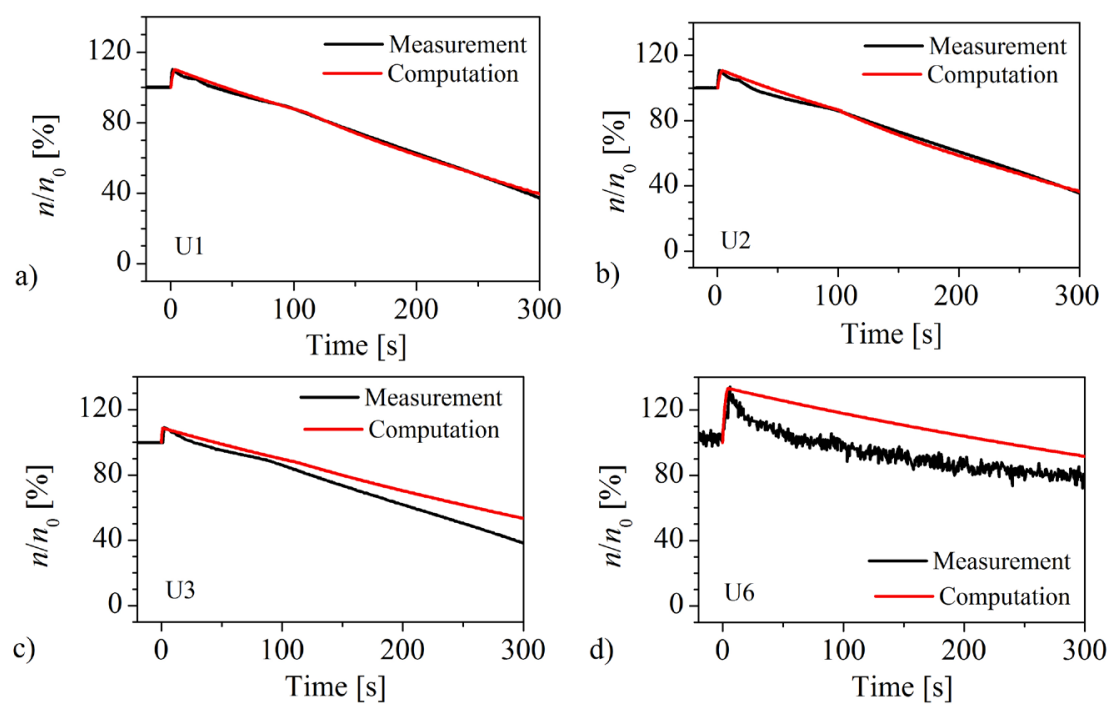

Fig. 10. Rotational speed change ( $n_{0}=375 \mathrm{~min}^{-1}, \mathrm{U} 1, \mathrm{U} 2$, U3 and $\left.n_{0}=428 \mathrm{~min}^{-1}, \mathrm{U} 6\right)$ during plant emergency shut-down from $P_{0}=303.54 \mathrm{MW}$ 
speed rise by using the results from the first step. The turbine model takes into account friction losses in the shaft bearings and ventilation losses in the turbine housing [6]. From comparisons of head changes at the downstream end of the penstocks, it can be seen that CBM yields only slightly better results. It can be concluded that inclusion of unsteady friction into numerical models is not necessary when relatively slow transients are considered at initially high Reynolds number flows (106 [6] to $10^{7}$ (this paper)). In addition, the model accurately simulates the changes of the water level in the surge tank. During power plant shut-down, there will be no spillage of water from the surge tank overflow nor surge tank emptying and air inflow into the concrete tunnel. Regarding the units' speed change, the numerical results agree well with the results of measurements for the refurbished units. The discrepancies between the results for the worn-out units are larger due to increased dissipation torque. It may be concluded that the developed numerical model gives good agreement with the results of measurements and, as such, it is recommended for the use in engineering practice for hydropower plants with Pelton turbines.

\section{ACKNOWLEDGEMENTS}

The authors gratefully acknowledge Institute Jaroslav Černi and members of the Electric Power Supply Company Modernization team for the authorization to publish results obtained during the measurement campaign. Support of the Slovenian Research Agency (ARRS) and the Ministry of Science of Montenegro (MSM) conducted through the project BI-ME/14-15-016 (ARRS, MSM) and the programme P2-0162 (ARRS) is also acknowledged.

\section{REFERENCES}

[1] Arrington, R.M. (1999). Failure of water-operated needle valves at Bartlett Dam and Oneida station hydroelectric plant. Proceedings of 3rd ASME/ JSME Joint Fluid Engineering Conference, San Francisco, p. 385-390.

[2] Adamkowski, A. (2001). Case study: Lapino powerplant penstock failure. ASCE Journal of Hydraulic Engineering, vol. 127, no. 7, p. 541-555, Dol:10.1061/ (ASCE)07339429(2001)127:7(547).

[3] Russell, W.R. (2010). Restoring Sayano-Shushenskaya. HRWHydro Review Worldwide, vol. 18, no. 1, p. 12-20.

[4] Bissel, C., Vullioud, G., Weiss, E., Heimann, A., Chene, O., Dayer, J.-D. and Nicolet, C. (2011). Recommissioning of the Bieudron powerplant. The International Journal on Hydropower \& Dams, vol. 18, no. 3, p. 82-85.
[5] Vereide, K., Svingen, B., Guddal, R. (2015). Case study: Damaging effects of increasing the installed capacity in an existing hydropower plant. Proceedings of the $12^{\text {th }}$ International Conference on Pressure Surges, Dublin, p. 417424.

[6] Karadžić, U., Bergant, A., Vukoslavčević, P. (2009). A novel Pelton turbine model for water hammer analysis. Strojniški Vestnik - Journal of Mechanical Engineering, vol. 55, no. 6, p. 369-380.

[7] Wylie, E.B., Streeter, V.L. (1993). Fluid Transients in Systems, Prentice Hall, Englewood Cliffs.

[8] Chaudhry, M.H. (2014). Applied Hydraulic Transients, Springer, New York, D0l:10.1007/978-1-4614-8538-4.

[9] Zielke, W. (1968). Frequency-dependent friction in transient pipe flow. ASME Journal of Basic Engineering, vol. 90, no. 1, p. 109-115, DOI:10.1115/1.3605049.

[10] Vardy, A.E., Brown, J.M.B. (2003). Transient turbulent friction in smooth pipe flows. Journal of Sound and Vibration, vol. 259, no. 5, p. 1011-1036, D0l:10.1006/jsvi.2002.5160.

[11] Vítkovský, J.P., Bergant, A., Simpson, A.R., Lambert, M.F. (2006). Systematic evaluation of one-dimensional unsteady friction models in simple pipelines. ASCE Journal of Hydraulic Engineering, vol. 132, no. 7, p. 696-708, Dol:10.1061/ (ASCE)0733-9429(2006)132:7(696).

[12] Adamkowski, A., Lewandowski, M. (2006). Experimental examination of unsteady friction models for transient pipe flow simulation. ASME Journal of Fluids Engineering, vol. 128, no. 6, p. 1351-1363, Dol:10.1115/1.2354521.

[13] Riasi, A., Raisee, M., Nourbekhsh, A. (2010). Simulation of transient flow in hydroelectric power plants using unsteady friction. Strojniški vestnik - Journal of Mechanical Engineering, vol. 56, no. 6, p. 377-384.

[14] Duan, H.-F., Ghidaoui, M.S, Lee, P.J., Tung, Y.K. (2012). Relevance of unsteady friction to pipe size and length in pipe fluid transients. ASCE Journal of Hydraulic Engineering, vol. 138, no. 2, p. 154-166, DOI:10.1061/(ASCE)HY.1943900.0000497 .

[15] Meniconi, S., Duan, H.F., Brunone, B., Ghidaoui, M.S., Lee, P.J., Ferrante, M. (2014). Further developments in rapidly decelerating turbulent flow modelling. ASCE Journal of Hydraulic Engineering, vol. 140, no. 7, p. 1-9, Dol:10.1061/ (ASCE)HY.1943-7900.0000880.

[16] Vardy, A.E. (2018). Acceleration-dependent unsteady friction revisited. Proceedings of the $13^{\text {th }}$ International Conference on Pressure Surges, Bordeaux, p. 265-282.

[17] Trikha, A.K. (1975). An efficient method for simulating frequency-dependent friction in transient liquid flow. ASME Journal of Fluids Engineering, vol. 97, no. 1, p. 97-105, Dol:10.1115/1.3447224.

[18] Zarzycki, Z. (1997). Hydraulic resistance of unsteady turbulent liquid flow in pipelines. Proceedings of the 3 rd International Conference on Water Pipeline Systems, The Hague, p. 163178.

[19] Vardy, A.E., Brown, J.M.B. (2004). Transient turbulent friction in fully rough pipe flows. Journal of Sound and Vibration, vol. 270, no. 1-2, p. 233-257, DOl:10.1016/S0022-460X(03)00492-9.

[20] Vítkovský, J., Stephens, M., Bergant, A., Lambert, M., Simpson, A. (2004). Efficient and accurate calculation of Zielke and 
Vardy-Brown unsteady friction in pipe transients. Proceedings of the 9th International Conference on Pressure Surges, Chester, p. 405-419.

[21] Urbanowicz, K. (2017). Analytical expressions for effective weighting functions used during simulations of water hammer. Journal of Theoretical and Applied Mechanics, vol. 55, no. 3, p. 1029-1040, D0l:10.15632/jtam-pl.55.3.1029.

[22] Urbanowicz, K. (2018). Fast and accurate modelling of frictional transient pipe flow. Journal of Applied Mathematics and Mechanics, vol. 98, no. 5, p. 802-823, D0l:10.1002/ zamm.201600246.

[23] Starinac, D., Džopalić, D., Predić, Z., Gajić, A., Vojt, P., Dimitrijević, M. (2011). Final report on in-situ measurement campaign at Perućica HPP, Montenegro - Part 2: Pressurized system. Jaroslav Černi Institute for the Development of Water Resources (JCl), Belgrade.

[24] Starinac, D., Žugić, D., Predić, Z., Gajić, A., Džopalić, D., Vojt, P. (2012). In-situ measurement campaign at the Perućica hydropower plant in Montenegro - Part 2: Pressurized system. Water Research and Management, vol. 2, no. 4, p. 3-17.

[25] Nicolet, C., Vullioud, G., Weiss, E., Bocherens, E., Dayer, J.-D., Chene, 0. (2012). Transient analysis of Cleuson-Dixence power plant and injector closure in the reflection time. Proceedings of the 11th International Conference on Pressure Surges, Lisbon, p. 27-41. 